J. Dairy Sci. 92:5720-5729

doi:10.3168/jds.2009-2069

(c) American Dairy Science Association, 2009.

\title{
Effects of milk fat composition, DGAT1, and SCD1 on fertility traits in Dutch Holstein cattle
}

\author{
R. M. Demeter, ${ }^{*} \dagger^{1}$ G. C. B. Schopen, ${ }^{*}$ A. G. J. M. Oude Lansink, $\dagger$ M. P. M. Meuwissen, $\dagger$ \\ and J. A. M. van Arendonk* \\ *Animal Breeding and Genomics Centre, Wageningen University, $6700 \mathrm{AH}$, Wageningen, the Netherlands \\ †Business Economics Group, Wageningen University, 6706 KN, Wageningen, the Netherlands
}

\begin{abstract}
Recently, selective breeding was proposed as a means of changing the fatty acid composition of milk to improve its nutritional quality. Before implementing such breeding objectives, effects on other economically important traits should be investigated. The objectives of this study were to examine 1) the effect of milk fat composition, and 2) the effect of polymorphisms of DGAT1 and $S C D 1$ genes on female fertility in commercial Dutch Holstein-Friesian cattle. Data on 1,745 first-lactation cows were analyzed by fitting linear mixed models. We found that higher concentrations of trans fatty acids within total milk fat negatively affected reproductive performance. Furthermore, results suggested a potential effect of the DGAT1 polymorphism on nonreturn rates for insemination 28 and $56 \mathrm{~d}$ after the first service. Our results can be used to assess the correlated effects of breeding for improved milk fat composition on reproduction, thereby allowing for better evaluation of breeding programs before implementation.
\end{abstract}

Key words: dairy cattle, milk fat composition, DGAT1, SCD1

\section{INTRODUCTION}

Because of biotechnological advances and a more complete knowledge of the cattle genome, new opportunities exist to produce raw milk with specific characteristics (Boland et al., 2001; Creamer et al., 2002). By using selective breeding, different types of raw milk can be produced to meet specific consumer needs or industrial demands. Recently, the opportunities to use selective breeding to change the fatty acid (FA) composition of milk have been investigated extensively. Changing the milk FA profile can improve the nutritional quality of milk and thus can lead to improved dairy products for human health.

Received January 23, 2009.

Accepted July 3, 2009.

${ }^{1}$ Corresponding author: robert.demeter@wur.nl
Selective breeding to change milk FA composition can take 2 primary directions. First, cows can be selected for an individual milk FA or for a group of milk FA, because several milk FA have recently been shown to have genetic variation within various US (Bobe et al., 2008), Belgian (Soyeurt et al., 2007, 2008), and Dutch (Stoop et al., 2008) dairy cattle breeds. Second, cows can be selected for particular genotypes. Two genes have recently been suggested as candidates: the gene coding for acyl-coenzyme A:diacylglycerol acyltransferase 1 (DGAT1) and the gene coding for stearoyl-coenzyme A desaturase 1 ( $\boldsymbol{S C D 1})$. The DGAT1 gene is located on chromosome 14 in cattle (Grisart et al., 2002; Winter et al., 2002) and plays a key role in triacylglycerol synthesis. A lysine-to-alanine polymorphism in DGAT1 (K232A) has been shown to affect milk FA composition (Schennink et al., 2007) and to explain some of the genetic variation in the milk fat unsaturation indices in Dutch Holstein cows (Schennink et al., 2008). The $S C D 1$ gene, which codes for a key enzyme in the cellular biosynthesis of monounsaturated FA, is located on chromosome 26 in cattle (Chung et al., 2000). An alanine-to-valine polymorphism in $S C D 1(\mathbf{A 2 9 3 V})$ has been found to influence milk FA composition in various Italian breeds (Mele et al., 2007; Moioli et al., 2007; Macciotta et al., 2008) and in Dutch Holstein cows (Schennink et al., 2008).

Before selecting for specific milk FA or candidate genes, however, effects on other economically important traits should be investigated. A relevant trait to consider is the reproductive performance of cows, given its high economic importance to dairy owners and managers (Lehenbauer and Oltjen, 1998). Little (and contradictory) information is available on the effects of DGAT1 variants on fertility traits (Ashwell et al., 2004; Kaupe et al., 2004; Wathes et al., 2008). Kaupe et al. (2007) found that the $\mathrm{K}$ allele had a negative effect on maternal nonreturn rate. Oikonomou et al. (2009), however, showed that the A allele increased the number of inseminations per conception and the presence of reproductive problems, and decreased the conception rate in the first $305 \mathrm{~d}$ of lactation. To our knowledge, 
estimates of the effects of milk FA composition and $S C D 1$ variants on the reproductive traits of dairy cattle are missing from the literature. The objectives of this study were to examine 1 ) the effect of milk fat composition, and 2) the effect of the DGAT1 K232A polymorphism and the SCD1 A293V polymorphism on fertility traits in commercial Holstein-Friesian dairy cattle in the Netherlands.

\section{MATERIALS AND METHODS}

\section{Animals}

We used data from the Dutch Milk Genomics Initiative, which focuses on the genetic background of detailed milk composition (Schennink et al., 2007; Stoop et al., 2007; Schopen et al., 2009). Data regarding 1,745 first-lactation cows distributed among 394 commercial herds throughout the Netherlands were collected. Participation invitations to the farms were based mainly on pedigree according to the database of the cooperative cattle improvement organization CRV (Arnhem, the Netherlands), which provided records on pedigree, yield, and reproduction. Each cow was more than $87.5 \%$ Holstein-Friesian. The cows descended from 1 of either 5 proven bulls (807 cows), 50 test bulls (771 cows), or 15 additional proven bulls (167 cows). Offspring from the last group of bulls were added to ensure sampling of at least 3 cows per herd. Further details on the animals used in this study are provided by Stoop et al. (2007).

\section{Phenotypes}

From the records on reproductive performance, the following 8 fertility traits were derived: interval (d) between the first and second calving $(\mathbf{C I})$, interval (d) between calving and the first insemination (DFS), number of inseminations (NINS), nonreturn rate $(0 / 1)$ for insemination $28 \mathrm{~d}$ after the first insemination (NR28), nonreturn rate $(0 / 1)$ for insemination $56 \mathrm{~d}$ after the first insemination (NR56), nonreturn rate (0/1) for insemination $90 \mathrm{~d}$ after the first insemination (NR90), rate $(0 / 1)$ of calving after the first insemination (CFI), and rate $(0 / 1)$ of calving after any inseminations (CR). Records for CI were considered missing if an animal did not have a known next calving date, or if the CI was shorter than $300 \mathrm{~d}$ or longer than $800 \mathrm{~d}$. Records for DFS were set to missing if the DFS was smaller than 20 d or greater than $300 \mathrm{~d}$. The NINS was set to missing if its value was 0 or greater than 10 . These criteria were applied to exclude unrealistic, unrepresentative, or erroneous records under Dutch conditions (Calus et al., 2005).
Cows were milked twice a day, and a morning milk sample from each cow was analyzed between February and March 2005. Each cow was between 66 and 282 d in lactation. Milk FA composition was measured by gas chromatography at the COKZ Laboratory (Leusden, the Netherlands) as described by Schennink et al. (2007). The FA were expressed as a proportion of total fat weight. Fatty acids included in this study were grouped according to their relevance to human health (German and Dillard, 2006). Fat and protein concentrations were measured by infrared spectroscopy with a Fourier-transform interferogram (MilkoScan FT 6000, Foss Electric, Hillerød, Denmark) at a Milk Control Station (Zutphen, the Netherlands). Furthermore, lactation yield records based on 305-d production for milk, protein, and fat were provided by CRV. In total, data regarding milk FA composition and the 5 production traits were missing for 19 animals.

\section{Genotypes}

Blood samples for DNA isolation were collected between April and June 2005. Genotyping of the DGAT1 and the $S C D 1$ polymorphisms were performed as described by Schennink et al. (2007) and Schennink et al. (2008), respectively. Because either no DNA sample was available or the sample could not be genotyped unambiguously, the genotype for DGAT1 was missing for 12 animals, and the genotype for $S C D 1$ was missing for 66 animals. When studying the effects of candidate gene polymorphisms, we also accounted for production traits (see the Statistical Analysis section below). To study the effects of the genes consistently, therefore, animals were excluded if no information was available on the 5 milk production traits.

Two data sets were formulated and used in this study. The first data set, which included 1,726 animals, was used to study the effects of milk FA composition and the DGAT1 polymorphism on fertility traits. Descriptive statistics of FA and milk production traits of the 1,726 animals are provided in Table 1 . The average 305d milk yield was $7,623 \mathrm{~kg}$, and 305 -d protein and fat yields were 262 and $327 \mathrm{~kg}$, respectively. Protein and fat percentages averaged 3.5 and $4.4 \%$, respectively. The reproductive performance of the 1,726 cows in the first data set is described in Table 2. The average length of the calving interval was $411 \mathrm{~d}$, and the mean interval between calving and the first insemination was approximately 90 d. Approximately $10 \%$ of the cows did not have a second calving. The second data set included 1,661 animals and was used to study the effects of the $S C D 1$ polymorphism; descriptive statistics for the second data set are not shown because they are similar to those of the first data set. 
Table 1. Descriptive statistics of individual fatty acids, fatty acid groups, and production traits of 1,726 firstlactation Dutch Holstein-Friesian cows

\begin{tabular}{|c|c|c|c|c|}
\hline Trait & Mean & Minimum & Maximum & $\mathrm{SD}$ \\
\hline \multicolumn{5}{|l|}{ Fatty acid (\%, wt/wt) } \\
\hline $\mathrm{C} 4: 0$ & 3.51 & 2.44 & 4.57 & 0.28 \\
\hline $\mathrm{C} 5$ to $\mathrm{C} 15^{1}$ & 1.47 & 0.72 & 3.90 & 0.32 \\
\hline $\mathrm{C} 6$ to $\mathrm{C} 12^{2}$ & 10.73 & 5.10 & 15.50 & 1.24 \\
\hline C14:0 & 11.62 & 6.17 & 14.94 & 0.93 \\
\hline C16:0 & 32.60 & 22.86 & 42.95 & 2.85 \\
\hline C18:0 & 8.72 & 3.19 & 17.12 & 1.43 \\
\hline $\mathrm{C} 18 \mathrm{u}^{3}$ & 22.35 & 15.29 & 41.14 & 2.57 \\
\hline $\mathrm{CLA}^{4}$ & 0.40 & 0.02 & 1.25 & 0.11 \\
\hline $\mathrm{TFA}^{5}$ & 1.64 & 0.75 & 7.74 & 0.41 \\
\hline SFA/UFA ${ }^{6}$ & 2.75 & 1.08 & 4.16 & 0.36 \\
\hline \multicolumn{5}{|l|}{ Production trait } \\
\hline 305-d milk yield ${ }^{7}(\mathrm{~kg})$ & $7,622.71$ & $3,970.00$ & $12,404.00$ & $1,207.57$ \\
\hline $305-d$ protein yield ${ }^{7}(\mathrm{~kg})$ & 262.44 & 149.00 & 404.00 & 40.22 \\
\hline 305-d fat yield $7(\mathrm{~kg})$ & 326.64 & 170.00 & 509.00 & 48.55 \\
\hline Protein concentration $^{8}(\%)$ & 3.50 & 2.67 & 4.59 & 0.30 \\
\hline Fat concentration ${ }^{8}(\%)$ & 4.36 & 1.46 & 9.08 & 0.70 \\
\hline
\end{tabular}

${ }^{1} \mathrm{C} 5$ to $\mathrm{C} 15$ includes the saturated fatty acids C5:0, C7:0, C9:0, C11:0, C13:0, and C15:0.

${ }^{2} \mathrm{C} 6$ to $\mathrm{C} 12$ includes the saturated fatty acids C6:0, C8:0, C10:0, and $\mathrm{C} 12: 0$.

${ }^{3} \mathrm{C} 18 \mathrm{u}$ includes the unsaturated $\mathrm{C} 18$ fatty acids C18:1 trans-6; C18:1 trans-9; C18:1 trans-10; C18:1 trans-11; C18:1 cis-9; C18:1 cis-11; C18:1 cis-12; C18:1 cis-13; C18:2 cis-9,12; C18:3 cis-9,12,15; C18:2 cis-9, trans-11; and C18:2 trans-10, cis-12.

${ }^{4}$ Conjugated linoleic acid (CLA) includes C18:2 cis-9, trans-11.

${ }^{5}$ Trans fatty acids (TFA) include C16:1 trans-9, C18:1 trans-6, C18:1 trans-9, C18:1 trans-10, and C18:1 trans-11.

${ }^{6}$ Saturated fatty acids (SFA) include C4:0, C5:0, C6:0, C7:0, C8:0, C9:0, C10:0, C11:0, C12:0, C13:0, C14:0 iso, C14:0, C15:0 anteiso, C15:0, C16:0 iso, C16:0, C17:0 iso, C17:0, C18:0, C20:0, C21:0, and C22:0. Unsaturated fatty acids (UFA) include C10:1; C12:1; C14:1 cis-9; C16:1 trans-9; C16:1 cis-9; C17:1 cis-9; C18:1 trans-6; C18:1 trans-9; C18:1 trans-10; C18:1 trans-11; C18:1 cis-9; C18:1 cis-11; C18:1 cis-12; C18:1 cis-13; C18:2 cis-9,12; C18:3 cis-9,12,15; C18:2 cis-9, trans-11; C18:2 trans-10, cis-12; C20:1 cis-11; C20:2 cis-11,14; C20:3 cis-8,11,14; and C22:1 cis-13.

${ }^{7}$ Provided by CRV (Arnhem, the Netherlands).

${ }^{8}$ Measured on single morning test-day milk samples collected between February and March 2005.

\section{Statistical Analysis}

Initial analyses were performed by using SAS 9.1 procedures (SAS Institute Inc., Cary, NC) to determine the significance of fixed effects. By using the MIXED procedure, linear mixed models were fitted as randomized block designs (Littell et al., 2006), with 394 herds as random blocks and individual cows as units of analysis.

Three modeling steps were performed. Model [1] was used to study the effects of milk fat composition on fertility. Model [1] included DIM (days between the date of first calving and the date of the milk sample), age at first calving, season of calving, and sire type (3 different sire groups: proven bulls, young bulls, or other proven bulls). Relationships between individuals were accounted for, and the total pedigree comprised 26,300 animals and was supplied by CRV. Variance components and fixed effect solutions were calculated by using the ASReml software package (Gilmour et al., 2006). Model [1] is written as

$$
\begin{gathered}
y_{i j k l m n o}=\mu+b_{1} \mathrm{DIM}_{\mathrm{i}}+b_{2} \mathrm{e}^{-0.05 \mathrm{DIM}}+b_{3} \mathrm{AFC}_{j}+b_{4} \mathrm{~F}_{k} \\
+\mathrm{SEA}_{l}+\mathrm{SCO}_{m}+\mathrm{HERD}_{n}+a_{o}+e_{i j k l m n o}
\end{gathered}
$$

where $y$ is the dependent variable (fertility trait), $\mu$ is the general mean, DIM is a fixed covariate accounting for the effect of DIM modeled with a Wilmink curve (Wilmink, 1987), AFC is a fixed covariate describing the effect of age at first calving, $\mathrm{F}$ is a fixed covariate accounting for the effect of one of the individual FA or FA groups, SEA is a fixed factor accounting for the effect of the calving season (June to August 2004, September to November 2004, or December 2004 to February 2005), SCO is a fixed factor capturing the effect of the differences in genetic level between proven bull daughters and young bull daughters, HERD is a random factor accounting for the effect of groups of animals sampled in the same herd, $a$ is a random factor accounting for the additive genetic effect of the given animal, and $e$ is the random residual effect. Each fertility trait was analyzed separately and each individual 
Table 2. Descriptive statistics for fertility traits of 1,726 first-lactation Dutch Holstein-Friesian cows

\begin{tabular}{lcrccc}
\hline Trait $^{1}$ & Cows (no.) & Mean & Minimum & Maximum & \multicolumn{1}{c}{ SD } \\
\hline CI & 1,551 & 410.57 & 304 & 795 & 74.93 \\
DFS & 1,721 & 90.02 & 21 & 284 & 36.76 \\
NINS & 1,724 & 2.09 & 1 & 10 & 1.50 \\
CR & 1,726 & 0.90 & & & \\
NR28 & 1,726 & 0.72 & & & \\
NR56 & 1,726 & 0.60 & & & \\
NR90 & 1,726 & 0.52 & & & \\
CFI & 1,726 & 0.44 & & & \\
\hline
\end{tabular}

${ }^{1}$ Fertility traits were interval between the first and second calving (CI), interval between calving and the first insemination (DFS), number of inseminations (NINS), calving rate (CR), nonreturn rate for insemination $28 \mathrm{~d}$ after the first service (NR28), nonreturn rate for insemination $56 \mathrm{~d}$ after the first service (NR56), nonreturn rate for insemination $90 \mathrm{~d}$ after the first service (NR90), and calving rate after the first insemination (CFI).

FA or FA group was also fitted separately (80 analyses in total).

To study the effects of the candidate genes, a model similar to model [1] was used. Model [2] excluded the covariate $\mathrm{F}$ and the correction for DIM (because no milk production trait measured on a single-day milk sample was involved), but included a fixed factor $\mathrm{G}$ that captured the effect of either the DGAT1 genotype (AA, AK, or $\mathrm{KK}$ ), or the $S C D 1$ genotype (AA, AV, or VV). Each fertility trait was analyzed separately and each polymorphism was also fitted separately (16 analyses in total). Model [2] is written as

$$
\begin{gathered}
y_{j l m n o p}=\mu+b_{1} \mathrm{AFC}_{j}+\mathrm{G}_{p}+\mathrm{SEA}_{l}+\mathrm{SCO}_{m} \\
+\operatorname{HERD}_{n}+a_{o}+e_{j l m n o p} .
\end{gathered}
$$

To study the effects of candidate genes adjusted for production traits, model [2] was extended with a fixed covariate $\mathrm{P}$ that corrected for the effect of 1 of the 5 milk production traits (model [3]). Each fertility trait was analyzed separately, each polymorphism was fitted separately, and the correction for each of the production traits was modeled separately (80 analyses in total). When correcting for protein or fat concentrations, model [3] also included DIM to correct for DIM (modeled with a Wilmink curve) because those 2 production traits were measured on single test-day milk samples. Model [3] is written as

$$
\begin{gathered}
y_{j l m n o p q}=\mu+b_{1} \mathrm{AFC}_{j}+b_{2} \mathrm{P}_{q}+\mathrm{G}_{p}+\mathrm{SEA}_{l}+\mathrm{SCO}_{m} \\
+\mathrm{HERD}_{n}+a_{o}+e_{j l m n o p q}
\end{gathered}
$$

Because the models above assumed normally distributed residuals, we also fitted generalized linear mixed models by using the GLIMMIX procedure in SAS 9.1 (Littell et al., 2006) for the count and binary variables. We assumed a Poisson distribution with a log link function for NINS and a binomial distribution with a logit link function for CR, NR28, NR56, NR90, and CFI. By fitting generalized linear models, the same fixed effects were significant as when the above linear models were fitted; therefore, we concluded that fitting linear mixed models was robust enough to handle the nonnormally distributed fertility traits.

In the above models, each individual FA, FA group, or polymorphism was fitted separately in a series of sequential analyses. In each analysis, the null hypothesis was of no FA or a polymorphism effect on the trait of interest. Because several fertility traits were analyzed, multiple hypothesis tests were performed. However, because of the correlations between those fertility traits, not all hypothesis tests were truly independent. To account for multiple testing, we considered the analyses of 1) CI, DFS, and NINS; 2) CR and CFI; and 3) NR28, NR56, and NR90 as 3 independent hypothesis tests. Bonferroni correction based on the method of Šidák (1967) was applied to account for multiple testing with regard to the 3 groups of fertility traits.

\section{RESULTS AND DISCUSSION}

\section{Effects of Milk Fat Composition}

To study the relationship between milk FA composition and reproductive performance, we used the FA profiles from 1,726 first-lactation Dutch Holstein-Friesian cows (model [1]). Estimated effects of the FA and their significance are presented in Table 3. The trans FA (TFA) were consistently found to affect reproduction, because this FA group had significant $(P<0.05)$ effects on several fertility traits. Greater TFA concentrations were associated with lower reproductive performance. More specifically, increased proportions of TFA within total fat resulted in larger (0.24) numbers of inseminations, lower $(3.8 \%)$ calving rates, lower $(5.5,9.6$, and $8.3 \%)$ nonreturn rates for insemination $(28,56$, and 90 $\mathrm{d}$ after the first service, respectively), and lower (7.5\%) calving rates after the first service. Associations between TFA concentration and NINS, NR56, NR90, and CFI were significant after Bonferroni correction. Although the relationships between TFA and CI and DFS were statistically nonsignificant, those results also suggest a possible negative effect of TFA for these traits.

In addition to the TFA, other significant $(P<0.05)$ relationships were found. The FA group C5 to C15 had a positive effect on reproduction because a greater proportion of C5 to C15 was associated with a higher (4.9\%) calving rate. Larger concentrations of the individual FA 
¿

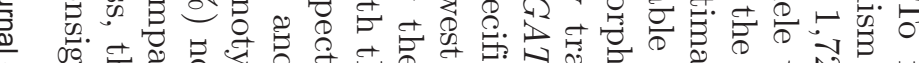

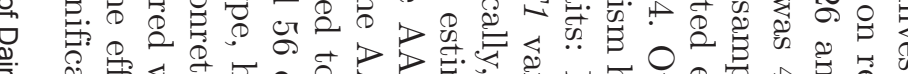

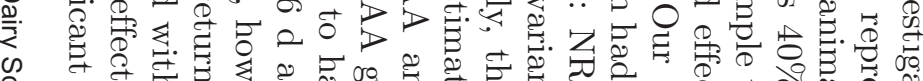
员

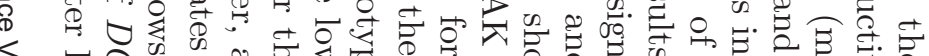

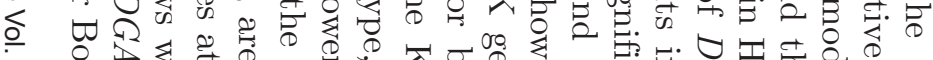

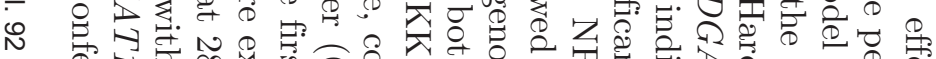
8 南

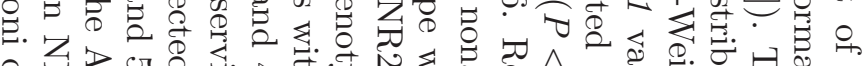

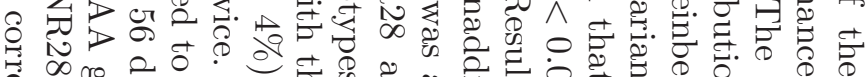

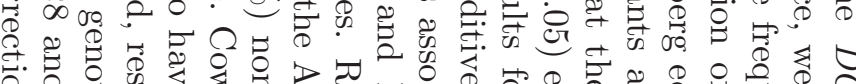

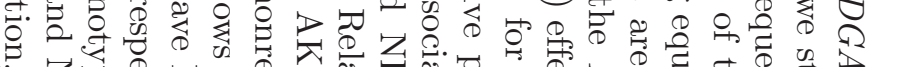

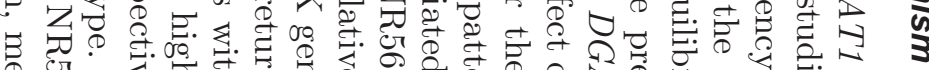

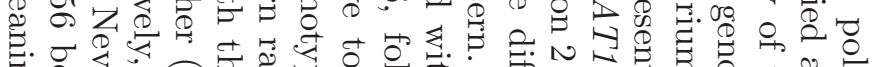

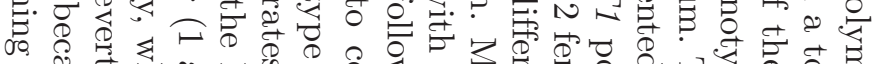

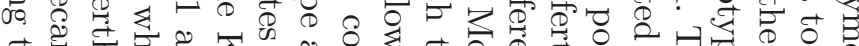

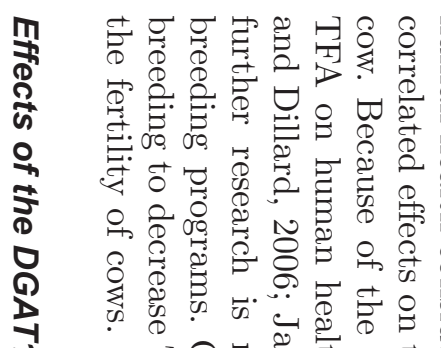

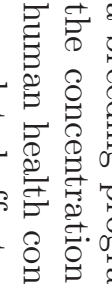

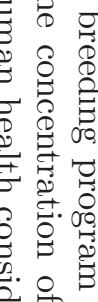

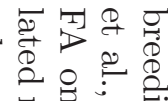

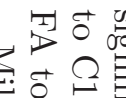
象 No

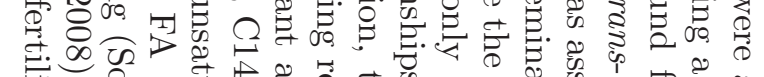

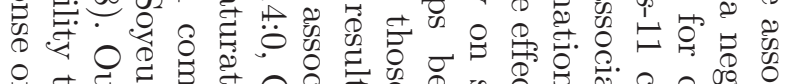

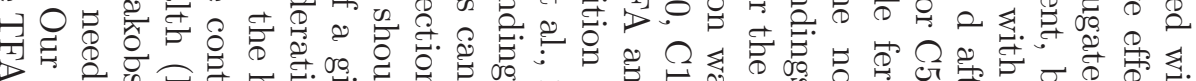

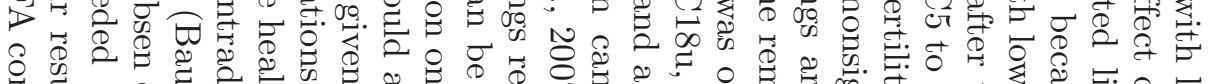

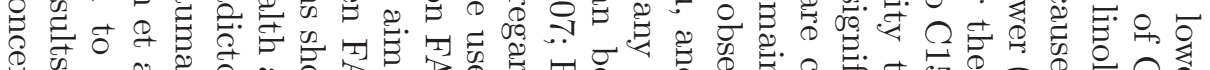

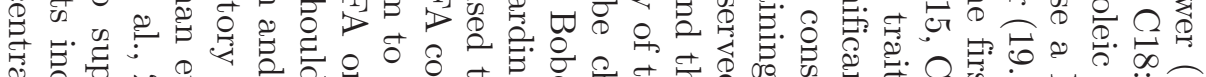

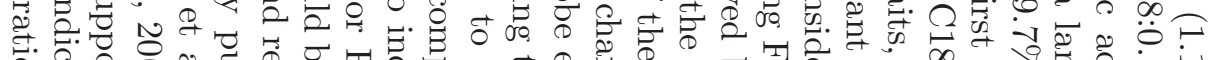

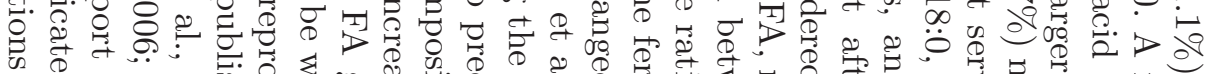

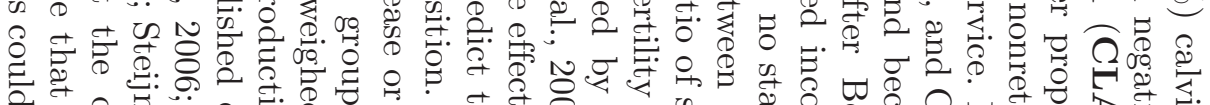

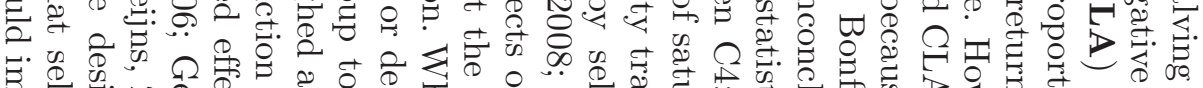

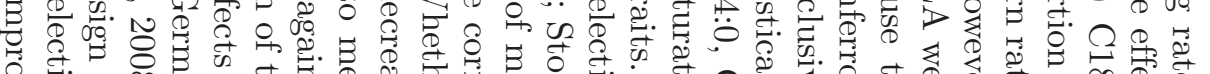

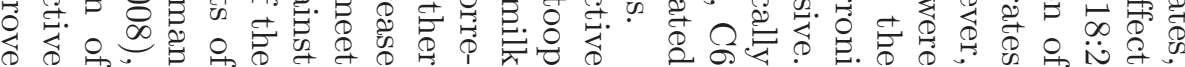

Table 3. Effects of individual fatty acids or fatty acid groups ${ }^{1}$ on fertility traits ${ }^{2}$ of 1,726 first-lactation Dutch Holstein-Friesian cows ${ }^{3}$

\begin{tabular}{lrrrrrrrr}
\hline Fatty acid & CI $(\mathrm{n}=1,551)$ & DFS $(\mathrm{n}=1,721)$ & NINS $(\mathrm{n}=1,724)$ & CR $(\mathrm{n}=1,726)$ & NR28 $(\mathrm{n}=1,726)$ & NR56 $(\mathrm{n}=1,726)$ & NR90 $(\mathrm{n}=1,726)$ & CFI $(\mathrm{n}=1,726)$ \\
\hline C4:0 & $-8.013 \pm 7.102$ & $-0.382 \pm 3.263$ & $-0.209 \pm 0.130$ & $-0.042 \pm 0.026$ & $0.011 \pm 0.040$ & $0.037 \pm 0.044$ & $0.059 \pm 0.045$ & $0.037 \pm 0.044$ \\
C5 to C15 & $5.804 \pm 6.211$ & $1.361 \pm 2.920$ & $0.049 \pm 0.114$ & $0.049 \pm 0.023^{*}$ & $-0.013 \pm 0.035$ & $-0.041 \pm 0.039$ & $-0.053 \pm 0.040$ & $-0.032 \pm 0.039$ \\
C6 to C12 & $-1.493 \pm 1.611$ & $0.042 \pm 0.757$ & $-0.009 \pm 0.030$ & $0.002 \pm 0.006$ & $-0.005 \pm 0.009$ & $-0.009 \pm 0.010$ & $-0.001 \pm 0.010$ & $-0.001 \pm 0.010$ \\
C14:0 & $-2.211 \pm 2.123$ & $-0.218 \pm 0.988$ & $0.013 \pm 0.039$ & $0.003 \pm 0.008$ & $-0.012 \pm 0.012$ & $-0.021 \pm 0.013$ & $-0.010 \pm 0.013$ & $-0.004 \pm 0.013$ \\
C16:0 & $0.303 \pm 0.703$ & $-0.113 \pm 0.328$ & $-0.009 \pm 0.013$ & $0.004 \pm 0.003$ & $0.000 \pm 0.004$ & $0.005 \pm 0.004$ & $0.003 \pm 0.004$ & $0.004 \pm 0.004$ \\
C18:0 & $-1.795 \pm 1.418$ & $-1.007 \pm 0.640$ & $0.005 \pm 0.025$ & $-0.011 \pm 0.005^{*}$ & $0.000 \pm 0.008$ & $-0.001 \pm 0.009$ & $0.006 \pm 0.009$ & $0.003 \pm 0.009$ \\
C18u & $0.916 \pm 0.791$ & $0.412 \pm 0.372$ & $0.014 \pm 0.014$ & $-0.003 \pm 0.003$ & $0.003 \pm 0.004$ & $0.000 \pm 0.005$ & $-0.003 \pm 0.005$ & $-0.004 \pm 0.005$ \\
CLA & $9.090 \pm 18.18$ & $8.531 \pm 8.656$ & $0.495 \pm 0.325$ & $-0.009 \pm 0.065$ & $-0.125 \pm 0.099$ & $-0.178 \pm 0.111$ & $-0.197 \pm 0.113 *$ & $-0.149 \pm 0.111$ \\
TFA & $5.037 \pm 5.148$ & $2.030 \pm 2.485$ & $0.240 \pm 0.089^{* *}$ & $-0.038 \pm 0.018^{*}$ & $-0.055 \pm 0.027^{*}$ & $-0.096 \pm 0.030^{* *}$ & $-0.083 \pm 0.031 * *$ & $-0.075 \pm 0.030^{* *}$ \\
SFA/UFA & $-7.706 \pm 5.530$ & $-4.150 \pm 2.567$ & $-0.072 \pm 0.100$ & $0.005 \pm 0.020$ & $-0.011 \pm 0.031$ & $0.000 \pm 0.034$ & $0.019 \pm 0.035$ & $0.022 \pm 0.034$ \\
\hline
\end{tabular}

${ }^{1}$ Groups of fatty acids are as follows: C5 to C15 includes the saturated fatty acids C5:0, C7:0, C9:0, C11:0, C13:0, and C15:0. C6 to C12 includes the saturated fatty acids C6:0, C8:0, C10:0, and C12:0. C18u includes the unsaturated C18 fatty acids C18:1 trans-6; C18:1 trans-9; C18:1 trans-10; C18:1 trans-11; C18:1 cis-9; C18:1 cis-11; C18:1 cis-12; C18:1 cis-13; C18:2 cis-9,12; C18:3 cis-9,12,15; C18:2 cis-9, trans-11; and C18:2 trans-10, cis-12. Conjugated linoleic acid (CLA) includes C18:2 cis-9, trans-11. Trans fatty acids (TFA) include C16:1 trans-9, C18:1 trans-6, C18:1 trans-9, C18:1 trans-10, and C18:1 trans-11. Saturated fatty acids (SFA) include C4:0, C5:0, C6:0, C7:0, C8:0, C9:0, C10:0, C11:0, C12:0, C13:0, C14:0 iso, C14:0, C15:0 anteiso, C15:0, C16:0 iso, C16:0, C17:0 iso C17:0, C18:0, C20:0, C21:0, and C22:0. Unsaturated fatty acids (UFA) include C10:1: C12:1: C14:1 cis9; C16:1 trans-9; C16:1 cis-9; C17:1 cis-9; C18:1 trans-6; C18:1 trans-9; C18:1 trans-10; C18:1 trans-11; C18:1 cis-9; C18:1 cis-11; C18:1 cis-12; C18:1 cis-13; C18:2 cis-9,12; C18:3 cis-9,12,15; C18:2 cis-9, trans-11; C18:2 trans-10, cis-12; C20:1 cis-11; C20:2 cis-11,14; C20:3 cis-8,11,14; and C22:1 cis-13.

Fertility traits were interval between the first and second calving (CI), interval between calving and the first insemination (DFS), number of inseminations (NINS), calving rate (CR), nonreturn rate for insemination $28 \mathrm{~d}$ after the first service (NR28), nonreturn rate for insemination $56 \mathrm{~d}$ after the first service (NR56), nonreturn rate for insemination $90 \mathrm{~d}$ after the first service (NR90), and calving rate after the first insemination (CFI).

Values after \pm signs are corresponding SE.

*Significant $(P<0.05)$; **significant after Bonferroni correction. 
Table 4. Effect of DGAT1 polymorphism on fertility traits $^{1}$ of 1,726 first-lactation Dutch Holstein-Friesian cows $^{2}$

\begin{tabular}{lccccc}
\hline Trait & Cows (no.) & $\begin{array}{c}\text { Predicted mean } \\
\text { of AA genotype }\end{array}$ & AA-AK & AA-KK & $P$-value \\
\hline CI & 1,551 & 398.21 & $4.65 \pm 4.22$ & $-0.61 \pm 5.82$ & 0.439 \\
DFS & 1,721 & 88.67 & $0.34 \pm 1.93$ & $-3.97 \pm 2.69$ & 0.212 \\
NINS & 1,724 & 1.79 & $0.06 \pm 0.08$ & $-0.05 \pm 0.11$ & 0.499 \\
CR & 1,726 & 0.89 & $0.03 \pm 0.02$ & $0.02 \pm 0.02$ & 0.140 \\
NR28 & 1,726 & 0.79 & $-0.06 \pm 0.02$ & $0.01 \pm 0.03$ & $0.024^{*}$ \\
NR56 & 1,726 & 0.68 & $-0.04 \pm 0.03$ & $0.05 \pm 0.04$ & $0.037^{*}$ \\
NR90 & 1,726 & 0.60 & $-0.02 \pm 0.03$ & $0.04 \pm 0.04$ & 0.275 \\
CFI & 1,726 & 0.53 & $-0.02 \pm 0.03$ & $0.04 \pm 0.04$ & 0.238 \\
\hline
\end{tabular}

${ }^{1}$ Fertility traits were interval between the first and second calving $(\mathrm{CI})$, interval between calving and the first insemination (DFS), number of inseminations (NINS), calving rate (CR), nonreturn rate for insemination 28 $\mathrm{d}$ after the first service (NR28), nonreturn rate for insemination $56 \mathrm{~d}$ after the first service (NR56), nonreturn rate for insemination $90 \mathrm{~d}$ after the first service (NR90), and calving rate after the first insemination (CFI).

${ }^{2}$ Values after \pm signs are corresponding SE.

*Significant $(P<0.05)$; nonsignificant after Bonferroni correction.

results are suggestive rather than conclusive. Associations between DGAT1 and the other fertility traits (CI, DFS, NINS, CR, NR90, and CFI) were statistically nonsignificant.

Because the DGAT1 polymorphism has a strong influence on milk fat content and other economically important milk production traits (Grisart et al., 2002; Winter et al., 2002), the effect of DGAT1 on fertility might be due to its correlated effect on the production traits. Further analyses, therefore, were performed by correcting for 1 of the 5 production traits (model [3]). Table 5 shows the estimated effects of the DGAT1 variants after correcting for production traits. Similar to the results above, the DGAT1 polymorphism had significant $(P<0.05)$ effects on NR28 and NR56, independent of which production trait was included in the model, although the results remained significant post Bonferroni correction only for NR28 after adjusting for fat concentrations. Moreover, the pattern of the estimated effects of different DGAT1 variants remained nonadditive (heterozygous disadvantage). Among the 3 genotypes, the AK variant was consistently associated with the lowest nonreturn rates at 28 and $56 \mathrm{~d}$. In short, the results of model [3] showed that the effect of $D G A T 1$ on milk production traits could not explain the association found between DGAT1 and fertility traits. Furthermore, the pattern of heterozygous animals being associated with lower nonreturn rates than homozygous animals remained. In conclusion, our results from model [2] and model [3] suggest a potential effect of DGAT1 on nonreturn rates for insemination 28 and $56 \mathrm{~d}$ after the first insemination.

Research has suggested that DGAT1 might play a role in reproduction. First, in a recent study Schmidt et al. (2006) found that DGAT1 was expressed in ovaries of hormone-treated rats. According to Schmidt et al. (2006), this finding suggests that DGAT1 might be important for the cellular proliferation and differentiation needed for reorganization in the ovary, because the gene is important for mitosis in other tissues and is induced by FSH. Second, bovine chromosome 14, where DGAT1 is located, has been studied extensively for QTL related to many economically important traits in cattle. Several studies have reported QTL, including $D G A T 1$, on bovine chromosome 14 that affect various (male) fertility traits in different dairy cattle breeds (Daetwyler et al., 2008; Kolbehdari et al., 2008). In short, there is evidence that DGAT1 could affect reproductive performance.

However, little is known about a direct association between the DGAT1 polymorphism and reproductive traits in cattle. Kaupe et al. (2007) studied the allelesubstitution effect on reproductive traits and showed a negative effect of the $\mathrm{K}$ allele on maternal nonreturn rate. Oikonomou et al. (2009), in contrast, found the A allele to be associated with a greater number of inseminations, lower conception rates, and a greater chance of reproductive problems. Kaupe et al. (2007) and Oikonomou et al. (2009) studied the gene substitution effect, meaning that the effects of the DGAT1 polymorphism were captured by linear regression coefficients estimated for the covariate corresponding to the number of copies of the substitution allele. The pattern of our results, however, was different from those 2 studies.

Investigating the effects of the DGAT1 polymorphism on fertility traits is important because this information can be used to evaluate selective breeding programs that exploit this polymorphism. As proposed by Schennink et al. (2007), the DGAT1 polymorphism can be used in selective breeding to change the milk FA composition. They demonstrated that increasing the frequency of the A allele would be desirable from a public health 
Table 5. Effect of DGAT1 polymorphism on fertility traits ${ }^{1}$ when correcting for production traits of 1,726 first-lactation Dutch Holstein-Friesian cows ${ }^{2}$

\begin{tabular}{|c|c|c|c|c|c|}
\hline Trait & Cows (no.) & $\begin{array}{c}\text { Predicted } \\
\text { mean of AA } \\
\text { genotype }\end{array}$ & $\mathrm{AA}-\mathrm{AK}$ & AA-KK & $P$-value \\
\hline \multicolumn{6}{|c|}{ Correcting for 305 -d milk yield } \\
\hline CI & 1,551 & 396.06 & $8.18 \pm 4.17$ & $8.54 \pm 5.84$ & 0.122 \\
\hline DFS & 1,721 & 88.25 & $1.80 \pm 1.92$ & $-0.40 \pm 2.73$ & 0.523 \\
\hline NINS & 1,724 & 1.79 & $0.11 \pm 0.08$ & $0.06 \pm 0.11$ & 0.393 \\
\hline $\mathrm{CR}$ & 1,726 & 0.89 & $0.03 \pm 0.02$ & $0.03 \pm 0.02$ & 0.110 \\
\hline NR28 & 1,726 & 0.79 & $-0.06 \pm 0.02$ & $-0.01 \pm 0.03$ & $0.021^{*}$ \\
\hline NR56 & 1,726 & 0.68 & $-0.04 \pm 0.03$ & $0.03 \pm 0.04$ & $0.051^{*}$ \\
\hline NR90 & 1,726 & 0.60 & $-0.03 \pm 0.03$ & $0.01 \pm 0.04$ & 0.360 \\
\hline CFI & 1,726 & 0.53 & $-0.03 \pm 0.03$ & $0.02 \pm 0.04$ & 0.328 \\
\hline \multicolumn{6}{|c|}{ Correcting for 305-d protein yield } \\
\hline CI & 1,551 & 397.37 & $5.36 \pm 4.18$ & $3.26 \pm 5.80$ & 0.446 \\
\hline DFS & 1,721 & 88.72 & $0.72 \pm 1.92$ & $-2.52 \pm 2.69$ & 0.432 \\
\hline NINS & 1,724 & 1.80 & $0.08 \pm 0.08$ & $0.01 \pm 0.11$ & 0.573 \\
\hline $\mathrm{CR}$ & 1,726 & 0.89 & $0.03 \pm 0.02$ & $0.03 \pm 0.02$ & 0.114 \\
\hline NR28 & 1,726 & 0.79 & $-0.06 \pm 0.02$ & $0.00 \pm 0.03$ & $0.025^{*}$ \\
\hline NR56 & 1,726 & 0.68 & $-0.04 \pm 0.03$ & $0.04 \pm 0.04$ & $0.051^{*}$ \\
\hline NR90 & 1,726 & 0.60 & $-0.02 \pm 0.03$ & $0.02 \pm 0.04$ & 0.360 \\
\hline CFI & 1,726 & 0.53 & $-0.02 \pm 0.03$ & $0.03 \pm 0.04$ & 0.304 \\
\hline \multicolumn{6}{|c|}{ Correcting for 305 -d fat yield } \\
\hline CI & 1,551 & 401.46 & $-0.62 \pm 4.31$ & $-7.32 \pm 5.92$ & 0.413 \\
\hline DFS & 1,721 & 90.06 & $-1.31 \pm 1.97$ & $-6.17 \pm 2.74$ & 0.072 \\
\hline NINS & 1,724 & 1.84 & $0.01 \pm 0.08$ & $-0.12 \pm 0.11$ & 0.459 \\
\hline $\mathrm{CR}$ & 1,726 & 0.90 & $0.03 \pm 0.02$ & $0.02 \pm 0.02$ & 0.241 \\
\hline NR28 & 1,726 & 0.78 & $-0.05 \pm 0.03$ & $0.01 \pm 0.03$ & $0.031^{*}$ \\
\hline NR56 & 1,726 & 0.67 & $-0.03 \pm 0.03$ & $0.06 \pm 0.04$ & $0.038^{*}$ \\
\hline NR90 & 1,726 & 0.59 & $-0.01 \pm 0.03$ & $0.04 \pm 0.04$ & 0.266 \\
\hline CFI & 1,726 & 0.53 & $-0.01 \pm 0.03$ & $0.05 \pm 0.04$ & 0.230 \\
\hline \multicolumn{6}{|c|}{ Correcting for protein concentration } \\
\hline CI & 1,551 & 400.32 & $7.59 \pm 4.33$ & $4.00 \pm 6.07$ & 0.212 \\
\hline DFS & 1,721 & 90.89 & $1.91 \pm 1.99$ & $-1.18 \pm 2.82$ & 0.375 \\
\hline NINS & 1,724 & 1.87 & $0.07 \pm 0.08$ & $-0.04 \pm 0.12$ & 0.497 \\
\hline $\mathrm{CR}$ & 1,726 & 0.90 & $0.03 \pm 0.02$ & $0.01 \pm 0.02$ & 0.300 \\
\hline NR28 & 1,726 & 0.78 & $-0.06 \pm 0.03$ & $0.01 \pm 0.04$ & $0.026^{*}$ \\
\hline NR56 & 1,726 & 0.67 & $-0.03 \pm 0.03$ & $0.06 \pm 0.04$ & $0.039^{*}$ \\
\hline NR90 & 1,726 & 0.57 & $-0.02 \pm 0.03$ & $0.04 \pm 0.04$ & 0.261 \\
\hline CFI & 1,726 & 0.53 & $-0.02 \pm 0.03$ & $0.04 \pm 0.04$ & 0.272 \\
\hline \multicolumn{6}{|c|}{ Correcting for fat concentration } \\
\hline CI & 1,551 & 397.75 & $12.29 \pm 4.52$ & $12.95 \pm 6.58$ & $0.023^{*}$ \\
\hline DFS & 1,721 & 90.06 & $2.96 \pm 2.08$ & $0.95 \pm 3.05$ & 0.307 \\
\hline NINS & 1,724 & 1.81 & $0.17 \pm 0.08$ & $0.14 \pm 0.12$ & 0.148 \\
\hline $\mathrm{CR}$ & 1,726 & 0.90 & $0.03 \pm 0.02$ & $0.02 \pm 0.03$ & 0.191 \\
\hline NR28 & 1,726 & 0.80 & $-0.08 \pm 0.03$ & $-0.03 \pm 0.04$ & $0.009^{* *}$ \\
\hline NR56 & 1,726 & 0.70 & $-0.07 \pm 0.03$ & $-0.01 \pm 0.04$ & $0.032^{*}$ \\
\hline NR90 & 1,726 & 0.60 & $-0.06 \pm 0.03$ & $-0.04 \pm 0.04$ & 0.135 \\
\hline CFI & 1,726 & 0.56 & $-0.06 \pm 0.03$ & $-0.03 \pm 0.04$ & 0.128 \\
\hline
\end{tabular}

${ }^{1}$ Fertility traits were interval between the first and second calving (CI), interval between calving and the first insemination (DFS), number of inseminations (NINS), calving rate (CR), nonreturn rate for insemination 28 $\mathrm{d}$ after the first service (NR28), nonreturn rate for insemination $56 \mathrm{~d}$ after the first service (NR56), nonreturn rate for insemination $90 \mathrm{~d}$ after the first service (NR90), and calving rate after the first insemination (CFI).

${ }^{2}$ Values after \pm signs are corresponding SE.

*Significant $(P<0.05) ; *$ significant after Bonferroni correction.

point of view because of the association of this variant with more unsaturated FA. According to Schennink et al. (2007), an increase in the frequency of the A allele could lead to a decrease in the C16:0 fraction and an increase in the unsaturated $\mathrm{C} 18$ fraction by approximately 5 to $10 \%$. Our results suggest that such a breeding goal could have consequences on reproduction.
Replacing cows with the AK genotype with cows with the AA genotype could be positive, because it could lead to improved nonreturn rates for insemination (28 and $56 \mathrm{~d}$ ) after the first service. However, increasing the frequency of the A allele by replacing cows with the KK genotype could have undesirable effect on reproductive performance. Because the allele frequencies found in 
Table 6. Effect of $S C D 1$ polymorphism on fertility traits $^{1}$ of 1,661 first-lactation Dutch Holstein-Friesian cows $^{2}$

\begin{tabular}{lccrcc}
\hline Trait & Cows (no.) & $\begin{array}{c}\text { Predicted mean } \\
\text { of AA genotype }\end{array}$ & \multicolumn{1}{c}{ AA-AV } & AA-VV & $P$-value \\
\hline CI & 1,493 & 398.21 & $2.75 \pm 4.05$ & $5.72 \pm 7.81$ & 0.676 \\
DFS & 1,656 & 87.22 & $0.41 \pm 1.88$ & $1.96 \pm 3.67$ & 0.866 \\
NINS & 1,659 & 1.84 & $-0.03 \pm 0.08$ & $-0.04 \pm 0.15$ & 0.928 \\
CR & 1,661 & 0.90 & $0.02 \pm 0.02$ & $0.04 \pm 0.03$ & 0.318 \\
NR28 & 1,661 & 0.76 & $0.01 \pm 0.02$ & $-0.01 \pm 0.05$ & 0.894 \\
NR56 & 1,661 & 0.67 & $-0.01 \pm 0.03$ & $-0.01 \pm 0.05$ & 0.923 \\
NR90 & 1,661 & 0.59 & $0.00 \pm 0.03$ & $-0.02 \pm 0.05$ & 0.935 \\
CFI & 1,661 & 0.53 & $-0.02 \pm 0.03$ & $-0.02 \pm 0.05$ & 0.814 \\
\hline
\end{tabular}

${ }^{1}$ Fertility traits were interval between the first and second calving $(\mathrm{CI})$, interval between calving and the first insemination (DFS), number of inseminations (NINS), calving rate (CR), nonreturn rate for insemination 28 $\mathrm{d}$ after the first service (NR28), nonreturn rate for insemination $56 \mathrm{~d}$ after the first service (NR56), nonreturn rate for insemination $90 \mathrm{~d}$ after the first service (NR90), and calving rate after the first insemination (CFI).

${ }^{2}$ Values after \pm signs are corresponding SE.

our sample suggest a considerably greater proportion of AK than KK animals, selecting for cows with the AA genotype seems to be the most desirable with regard to nutritional quality concerns and the reproductive performance of the cows.

\section{Effects of the SCD1 A293V Polymorphism}

To study the effects of the SCD1 polymorphism on fertility, we analyzed a sample of 1,661 first-lactation Dutch Holstein-Friesian cows (model [2]). The frequency of the A allele was approximately $73 \%$, and the genotypes were in Hardy-Weinberg equilibrium. The estimated effects of the $S C D 1$ variants are presented in Table 6 . As the results indicate, we found no significant effect on any of the reproductive traits. This finding was further reinforced by the results of the extended model correcting for production traits (model [3]; results not shown).

Stearoyl-CoA desaturase (SCD), which is also called $\Delta^{9}$-desaturase, is an enzyme that introduces a cis double bond between carbon atoms C9 and C10 of the FA chain, thereby desaturating saturated FA to monounsaturated FA. Several SCD genes have been isolated in several species, and the isoforms are differentially distributed in different tissues.

Recent research has suggested that SCD isoforms might play a role in female fertility in mammalian species. Moreau et al. (2006) were the first to show the expression of SCD1 and SCD2 in the rat ovary. They found several-fold higher expression for SCD2 than for SCD1, indicating that SCD2 is responsible for $\Delta^{9}$ desaturase activity in the ovary. Because the oocyte is rich in unsaturated FA, according to Moreau et al. (2006), monounsaturated FA formed in the cumulus cells via SCD2 activation can play a vital role in fertility. This assertion is based on the fact that removal of cumulus cells at the time of fertilization often results in lower fertilization rates in most mammalian species (Wang and Niwa, 1995; Zhang et al., 1995).

In the literature we found only one genome-wide scan that reported a QTL on bovine chromosome 26 (where SCD1 is located) affecting female reproductive performance. Thomasen et al. (2008) detected a QTL on bovine chromosome 26 that affects calving traits in Danish Holstein cattle.

To our knowledge, however, no previous study investigating a direct association between any isoforms of the SCD gene and reproductive traits in any mammalian species has been published. The present study did not detect any significant association between the $\Delta^{9}$-desaturase isoform SCD1 and female reproductive performance in dairy cattle. Because of its effect on milk FA composition, $S C D 1$ has been considered as a candidate gene to be used in breeding programs for improving the nutritional value of milk (Mele et al., 2007; Moioli et al., 2007; Schennink et al., 2008). Our findings indicate that selection based on $S C D 1$ genotypes would not affect the reproductive performance of the cows.

\section{CONCLUSIONS}

The objective of this study was to examine the effect of milk fat composition, DGAT1, and SCD1 on fertility traits in commercial Dutch Holstein-Friesian dairy cattle. Data on 1,745 first-lactation cows were analyzed by fitting linear mixed models. Greater concentrations of TFA within total milk fat negatively affected reproductive performance. Our results suggest that DGAT1 has a potential effect on nonreturn rates for insemination 28 and $56 \mathrm{~d}$ after the first service. Results for DGAT1 display a nonadditive pattern, with heterozygous genotypes associated with lower estimates 
for nonreturn rates than homozygous genotypes. Our findings suggest that a breeding program selecting for animals with the AA genotype would be the most desirable with regard to the nutritional quality of milk and the reproductive performance of cows. Results of this study can be used to assess the (economic) effects of changing milk fat composition. Consequently, selective breeding programs can be better evaluated before implementation.

\section{ACKNOWLEDGMENTS}

This study is part of the Dutch Milk Genomics Initiative and the project Melk op Maat, funded by Wageningen University, the Dutch Dairy Association (NZO, Zoetermeer, the Netherlands), the cooperative cattle improvement organization CRV (Arnhem, the Netherlands), the Dutch Technology Foundation (STW, Utrecht, the Netherlands), the Dutch Ministry of Economic Affairs (The Hague, the Netherlands), and the Provinces of Gelderland (Arnhem, the Netherlands) and Overijssel (Zwolle, the Netherlands). The authors thank the owners of the herds, the Milk Control Station (Zutphen, the Netherlands), and CRV for their help in collecting the data. We also thank the 2 anonymous reviewers for their helpful suggestions and corrections.

\section{REFERENCES}

Ashwell, M. S., D. W. Heyen, T. S. Sonstegard, C. P. Van Tassell, Y. Da, P. M. VanRaden, M. Ron, J. I. Weller, and H. A. Lewin. 2004. Detection of quantitative trait loci affecting milk production, health, and reproductive traits in Holstein cattle. J. Dairy Sci. $87: 468-475$.

Bauman, D. E., A. L. Lock, B. A. Corl, C. Ip, A. M. Salter, and P. W. Parodi. 2006. Milk fatty acids and human health: potential role of conjugated linoleic acid and trans fatty acids. Pages 529-561 in Ruminant Physiology: Digestion, Metabolism and Impact of Nutrition on Gene Expression, Immunology and Stress. K. Sejrsen, T. Hvelplund, and M. O. Nielsen, ed. Wageningen Academic Publishers, Wageningen, the Netherlands.

Bobe, G., J. A. Minick Bormann, G. L. Lindberg, A. E. Freeman, and D. C. Beitz. 2008. Short communication: Estimates of genetic variation of milk fatty acids in US Holstein cows. J. Dairy Sci. 91:1209-1213.

Boland, M., A. MacGibbon, and J. Hill. 2001. Designer milks for the new millennium. Livest. Prod. Sci. 72:99-109.

Calus, M. P. L., J. J. Windig, and R. F. Veerkamp. 2005. Associations among descriptors of herd management and phenotypic and genetic levels of health and fertility. J. Dairy Sci. 88:2178-2189.

Chung, M., S. Ha, S. Jeong, J. Bok, K. Cho, M. Baik, and Y. Choi 2000. Cloning and characterization of bovine stearoyl CoA desaturase 1 cDNA from adipose tissues. Biosci. Biotechnol. Biochem. 64:1526-1530.

Creamer, L. K., L. E. Pearce, J. P. Hill, and M. J. Boland. 2002. Milk and dairy products in the 21st century. Prepared for the 50th anniversary of the Journal of Agricultural and Food Chemistry. J. Agric. Food Chem. 50:7187-7193.

Daetwyler, H. D., F. S. Schenkel, M. Sargolzaei, and J. A. B. Robinson. 2008. A genome scan to detect quantitative trait loci for economically important traits in Holstein cattle using two methods and a dense single nucleotide polymorphism map. J. Dairy Sci 91:3225-3236

German, J. B., and C. J. Dillard. 2006. Composition, structure and absorption of milk lipids: A source of energy, fat-soluble nutrients and bioactive molecules. Crit. Rev. Food Sci. Nutr. 46:57-92.

Gilmour, A. R., B. J. Gogel, B. R. Cullis, and R. Thompson. 2006 ASReml User Guide Release 2.0. VSN International Ltd., Hemel Hempstead, UK.

Grisart, B., W. Coppieters, F. Farnir, L. Karim, C. Ford, P. Berzi, N. Cambisano, M. Mni, S. Reid, P. Simon, R. Spelman, M. Georges, and R. Snell. 2002. Positional candidate cloning of a QTL in dairy cattle: Identification of a missense mutation in the bovine DGAT1 gene with major effect on milk yield and composition. Genome Res. 12:222-231.

Jakobsen, M. U., A. Bysted, N. L. Andersen, B. L. Heitmann, H. B. Hartkopp, T. Leth, K. Overvad, and J. Dyerberg. 2006. Intake of ruminant trans fatty acids and risk of coronary heart disease-An overview. Atheroscler. Suppl. 7:9-11.

Kaupe, B., H. Brandt, E. M. Prinzenberg, and G. Erhardt. 2007. Joint analysis of the influence of $C Y P 11 B 1$ and DGAT1 genetic variation on milk production, somatic cell score, conformation, reproduction, and productive lifespan in German Holstein cattle. J. Anim. Sci. 85:11-21.

Kaupe, B., A. Winter, R. Fries, and G. Erhardt. 2004. DGAT1 polymorphism in Bos indicus and Bos taurus cattle breeds. J. Dairy Res. 71:182-187.

Kolbehdari, D., Z. Wang, J. R. Grant, B. Murdoch, A. Prasad, Z. Xiu, E. Marques, P. Stothard, and S. S. Moore. 2008. A whole-genome scan to map quantitative trait loci for conformation and functional traits in Canadian Holstein bulls. J. Dairy Sci. 91:2844-2856.

Lehenbauer, T. W., and J. W. Oltjen. 1998. Dairy cow culling strategies: Making economical culling decisions. J. Dairy Sci. 81:264-271.

Littell, R. C., G. A. Milliken, W. W. Stroup, R. D. Wolfinger, and O. Schabenberger. 2006. SAS for Mixed Models. 2nd ed. SAS Inst. Inc., Cary, NC.

Macciotta, N. P. P., M. Mele, G. Conte, A. Serra, M. Cassandro, R. Dal Zotto, A. Cappio Borlino, G. Pagnacco, and P. Secchiari 2008. Association between a polymorphism at the stearoyl CoA desaturase locus and milk production traits in Italian Holsteins. J. Dairy Sci. 91:3184-3189.

Mele, M., G. Conte, B. Castiglioni, S. Chessa, N. P. P. Macciotta, A. Serra, A. Buccioni, G. Pagnacco, and P. Secchiari. 2007. Stearoylcoenzyme A desaturase gene polymorphism and milk fatty acid composition in Italian Holsteins. J. Dairy Sci. 90:4458-4465.

Moioli, B. G. Contarini, A. Avalli, G. Catillo, L. Orru, G. De Matteis, G. Masoero, and F. Napolitano. 2007. Short communication: Effect of stearoyl-coenzyme A desaturase polymorphism on fatty acid composition of milk. J. Dairy Sci. 90:3553-3558.

Moreau, C., P. Froment, L. Tosca, V. Moreau, and J. Dupont. 2006 Expression and regulation of the SCD2 desaturase in the rat ovary. Biol. Reprod. 74:75-87.

Oikonomou, G., K. Angelopoulou, G. Arsenos, D. Zygoyiannis, and G. Banos. 2009. The effects of polymorphisms in the DGAT1, leptin and growth hormone receptor gene loci on body energy, blood metabolic and reproductive traits of Holstein cows. Anim. Genet. 40:10-17.

Schennink, A., J. M. L. Heck, H. Bovenhuis, M. H. P. W. Visker, H. J. F. Van Valenberg, and J. A. M. van Arendonk. 2008. Milk fatty acid unsaturation: Genetic parameters and effects of stearoyl-CoA desaturase $(S C D 1)$ and acyl CoA:diacylglycerol acyltransferase 1 (DGAT1). J. Dairy Sci. 91:2135-2143.

Schennink, A., W. M. Stoop, M. H. P. W. Visker, J. M. L. Heck, H. Bovenhuis, J. J. Van der Poel, H. J. F. Van Valenberg, and J. A. M. van Arendonk. 2007. DGAT1 underlies large genetic variation in milk-fat composition of dairy cows. Anim. Genet. 38:467-473.

Schmidt, J., J. De Avila, and D. McLean. 2006. Regulation of protein tyrosine phosphatase 4a1, B-cell translocation gene 2, nuclear receptor subfamily $4 \mathrm{a} 1$ and diacylglycerol $O$-acyltransferase 1 by follicle stimulating hormone in the rat ovary. Reprod. Fertil. Dev. 18:757-765. 
Schopen, G. C. B., J. M. L. Heck, H. Bovenhuis, M. H. P. W. Visker, H. J. F. Van Valenberg, and J. A. M. van Arendonk. 2009. Genetic parameters for major milk proteins in Dutch Holstein-Friesians. J. Dairy Sci. 92:1182-1191.

Šidák, Z. 1967. Rectangular confidence regions for the means of multivariate normal distributions. J. Am. Stat. Assoc. 62:626633.

Soyeurt, H., P. Dardenne, F. Dehareng, C. Bastin, and N. Gengler. 2008. Genetic parameters of saturated and monounsaturated fatty acid content and the ratio of saturated to unsaturated fatty acids in bovine milk. J. Dairy Sci. 91:3611-3626.

Soyeurt, H., A. Gillon, S. Vanderick, P. Mayeres, C. Bertozzi, and N. Gengler. 2007. Estimation of heritability and genetic correlations for the major fatty acids in bovine milk. J. Dairy Sci. 90:44354442 .

Steijns, J. M. 2008. Dairy products and health: Focus on their constituents or on the matrix? Int. Dairy J. 18:425-435.

Stoop, W. M., H. Bovenhuis, and J. A. M. van Arendonk. 2007. Genetic parameters for milk urea nitrogen in relation to milk production traits. J. Dairy Sci. 90:1981-1986.

Stoop, W. M., J. A. M. van Arendonk, J. M. L. Heck, H. J. F. Van Valenberg, and H. Bovenhuis. 2008. Genetic parameters for major milk fatty acids and milk production traits of Dutch HolsteinFriesians. J. Dairy Sci. 91:385-394.
Thomasen, J. R., B. Guldbrandtsen, P. Sorensen, B. Thomsen, and M. S. Lund. 2008. Quantitative trait loci affecting calving traits in Danish Holstein cattle. J. Dairy Sci. 91:2098-2105.

Wang. W., and K. Niwa. 1995. Synergetic effects of epidermal growth factor and gonadotropins on the cytoplasmic maturation of pig oocytes in a serum-free medium. Zygote 3:345-350.

Wathes, D. C., J. S. Brickell, N. E. Bourne, A. Swali, and Z. Cheng. 2008. Factors influencing heifer survival and fertility on commercial dairy farms. Animal 2:1135-1143.

Wilmink, J. B. M. 1987. Adjustment of test-day milk, fat and protein yield for age, season and stage of lactation. Livest. Prod. Sci. $16: 335-348$.

Winter, A., W. Krämer, F. A. O. Werner, S. Kollers, S. Kata, G. Durstewitz, J. Buitkamp, J. E. Womack, G. Thaller, and R. Fries. 2002. Association of a lysine-232/alanine polymorphism in a bovine gene encoding acyl-CoA:diacylglycerol acyltransferase (DGAT1) with variation at a quantitative trait locus for milk fat content. Proc. Natl. Acad. Sci. USA 99:9300-9305.

Zhang, L., S. Jiang, P. J. Wozniak, X. Z. Yang, and R. A. Godke. 1995. Cumulus cell function during bovine oocyte maturation, fertilization, and embryo development in vitro. Mol. Reprod. Dev. 40:338-344. 